\title{
Volcanic Ash Reinforcement Concentration Effect on Thermal Properties of Polyvinyl Chloride Composites
}

\author{
S. FIDAN* \\ Kocaeli University, School of Civil Aviation, 41285 Kartepe/Kocaeli, Turkey
}

\begin{abstract}
This paper reports the results of experiments evaluating the thermal properties of volcanic ash (VA) reinforced polyvinyl chloride (PVC) composites with various concentrations. PVC matrix composites reinforced with various VA concentrations $(5,10,15,20$ and 25 wt.\%) were manufactured by using a twin screw micro-compounder and an injection molding machine. Thermogravimetric analysis (TGA) was used to monitor the changes in physical and chemical properties of VA reinforced PVC composites as a function of increasing temperature and time. Measuring the changes in weight of the material as a result of heating gives valuable information about thermal degradation of VA reinforced PVC composites. Therefore by using TGA, effect of volcanic ash concentration on thermal stability and degradation extent of PVC matrix composite was evaluated
\end{abstract}

DOI: $10.12693 /$ APhysPolA.127.1002

PACS: 81.05.Qk

\section{Introduction}

Poly(vinyl chloride) (PVC) is an extensively used thermoplastic material because of its valuable properties, such as superior mechanical and physical properties, high chemical and abrasion resistance, and is widely utilized in durable applications, e.g. for pipes, window profiles, house siding, wire cable insulation and flooring $[1,2]$. However, in the radical polymerization of the vinyl chloride, a number of isomeric forms and structural defects resulted from the formation of the main chain [3]. These anomalous structures could induce thermal instability of PVC during the polymer usage, because thermal dehydrochlorination of PVC often begins with internal allylic chloride and tertiary chloride structural defects in the main chain [2]. Hence the experimental studies about thermal stability of PVC are vital.

Recently, with increasing environmental awareness and expanding global waste problems, eco-friendly bio-fillers have been increasingly recognized as a promising alternative to inorganic fillers in the reinforcement of thermoplastic and biodegradable plastics $[4,5]$. Bio-fillers have several advantages compared to inorganic fillers, such as a non-hazardous nature, low cost, low density, low manufacture energy (low $\mathrm{CO}_{2}$ emission), renewability and biodegradability [4-6]. These bio-filler filled thermoplastics and biodegradable plastic composites, commonly called bio-composites and eco-composites, are experiencing fast growth in various applications such as automotive parts, outdoor decking products, window and door frames, consumer products, and so on [6-8].

Volcanic ash (VA) is formed during volcanic eruptions. Over the last decade the use of porous organic fillers such as VA were increased due to their environmental friendly

*e-mail: sinanfidandr@yahoo.com characteristics. As VA particles have high surface area due to their large porosity characteristic, they increase the effect of surface adhesion when they used as fillers in composites.

The aim of this study was to investigate the thermal properties of volcanic ash (VA) reinforced polyvinyl chloride $(\mathrm{PVC})$ composites with various concentrations by using thermogravimetric analysis (TGA).

\section{Materials and methods}

\subsection{Materials}

PVC used as the matrix resin for the microcompounding and injection molding was D100 TE provided by Ankara Granül Co. in Turkey. The D100 TE is an unfilled grade for extrusion applications and has a density of $1.37 \mathrm{~g} / \mathrm{cm}^{3}$. VA samples were taken from Guneydag tuff ring, which is located $13 \mathrm{~km}$ southwest of Nevsehir/Turkey. Nearly all vitric grains are angular and highly vesicular. Density and porosity parameters determined by helium pycnometer and mercury porosimeter are $1.8-2.4 \mathrm{~g} / \mathrm{cm}^{3}$ and $36-55 \%$, respectively.

\subsection{Sample preparation}

$\mathrm{PVC} / \mathrm{VA}$ composite materials were prepared by melt compounding and injection molding processes. DSM Xplore $15 \mathrm{ml}$ micro-compounder was used for melt compounding with a maximum processing temperature of $400{ }^{\circ} \mathrm{C}$ and a co-rotating twin screw speed of $250 \mathrm{rpm}$. DSM Xplore $12 \mathrm{ml}$ injection molding machine was used for injection molding of compounded melt. Maximum processing and mold temperatures are $400{ }^{\circ} \mathrm{C}$ and $200{ }^{\circ} \mathrm{C}$, respectively and also its maximum pressure capacity is 16 bar. All the samples were compounded at $195{ }^{\circ} \mathrm{C}$ with $40 \mathrm{rpm}$ of screw speed and then injected in to the mold at $50{ }^{\circ} \mathrm{C}$ with an injection pressure of 10 bar. 


\subsection{Thermogravimetric analysis (TGA)}

The thermogravimetric analysis (TGA) for PVC composite samples with different concentrations of VA were performed by TA Instruments Q50 TGA equipment. The samples about $10 \mathrm{mg}$ were heated from ambient $\left(25^{\circ} \mathrm{C}\right)$ to $600{ }^{\circ} \mathrm{C}$ at a heating rate of $20{ }^{\circ} \mathrm{C} / \mathrm{min}$ under a nitrogen atmosphere with flow rate of $50 \mathrm{ml} / \mathrm{min}$. From TGA curves, the thermal degradation characteristics were determined. The temperature at $10 \mathrm{wt} . \%$ loss $\left(T_{10}\right)$ was taken as the onset of degradation. And also the maximum degradation temperature $\left(T_{m}\right)$ was determined as the peak maximum obtained by the first-order derivative weight curve.

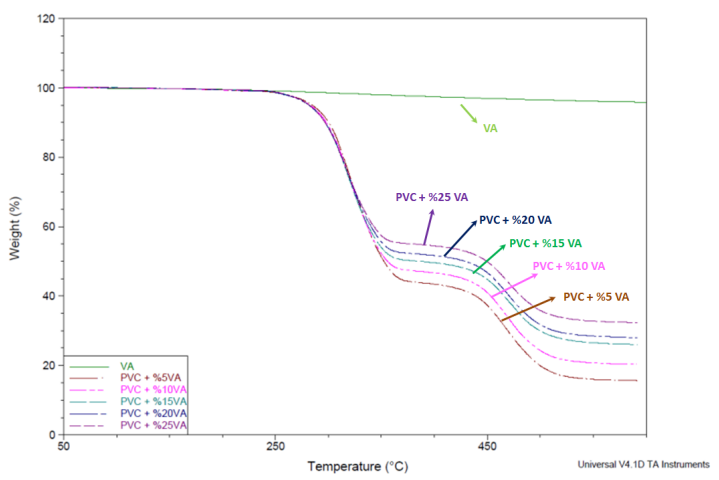

Fig. 1. Thermogravimetric curves and thermal stability properties of PPS composites with various VA concentrations.

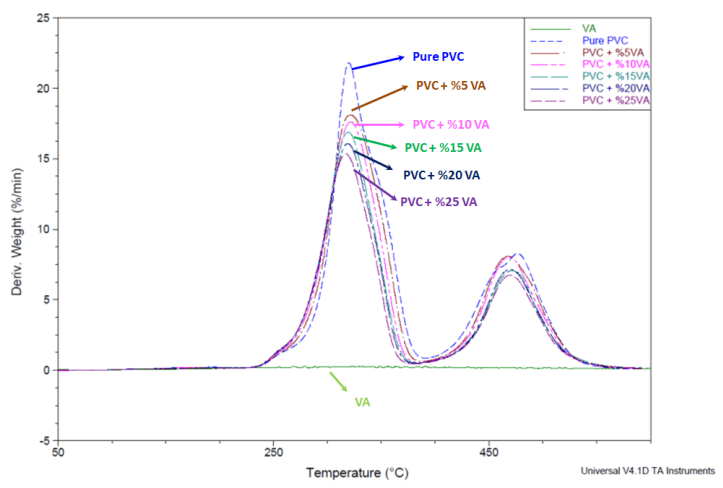

Fig. 2. Derivative weight versus temperature curves of PVC composites with various VA concentrations.

\section{Results and discussion}

To analyze the thermal stability of the prepared PVC/VA composites, TGA experiments were performed under nitrogen atmosphere. From the thermogravimetric curves shown in Fig. 1 and Fig. 2, it was found that $\mathrm{PVC}$ and its composites with different VA concentrations present a relatively good thermostability because no significant mass loss occurred until $250{ }^{\circ} \mathrm{C}$. As shown in Fig. 1, the VA particles exhibited no weight loss in this range of temperature; in contrast, PVC composites filled with various VA concentrations exhibited obvious weight loss. TGA curves of PVC composites reinforced with different concentrations of VA follow a degradation stage that initiates at $\approx 275^{\circ} \mathrm{C}$ and shows the maximum rate of weight loss at around $350{ }^{\circ} \mathrm{C}$. While the residual mass for $\% 5 \mathrm{VA}$ was about $18 \%$ of the initial weight, the residual mass for $\% 25$ VA concentrations was about $38 \%$ of the initial weight at $550{ }^{\circ} \mathrm{C}$. So, the residual weight increases with incorporation of filling VA material.

\section{Conclusions}

- Thermal stability of PVC composites were improved with incorporation of VA particles.

- VA particles exhibited no weight loss during TGA analysis in test temperatures (Test temperatures between $25{ }^{\circ} \mathrm{C}$ and $600{ }^{\circ} \mathrm{C}$ ).

- VA filler can be used up to $\% 25$ concentration with PVC composites in order to improve thermal stability.

\section{References}

[1] K.C. Mensker, G.T. Fedoseeva, The degradation and stabilization of $P V C$, Chemistry Press, USSR 1979.

[2] O. Vogl, G.C. Berry, Prog. Polym. Sci. 27, 2133 (2002).

[3] F. Gong, M. Feng, C. Zhao, S. Zhang, M. Yang, Polymer Degradationand Stability 84(2), 289 (2004).

[4] S. Mishra, A.K. Mohanty, L.T. Drzal, M. Misra, G. Hinrichsen, Macromol. Mater. Eng. 289, 955 (2004).

[5] H.-S. Kim, H.-J. Kim, J.-W. Lee, I.-G. Choi, Polym. Degrad. Stab. 91 (5), 1117 (2006).

[6] H. Demir, U. Atikler, D. Balkose, F. Tihminlioglu, Compos. Part A 37 (3), 447 (2006).

[7] J.A. Foulk, W.Y. Chao, D.E. Akin, R.B. Dodd P.A. Layton, J. Polym. Environ. 14 (1), 15 (2006).

[8] M. Pervaiz, M.M. Sain, Macromol. Mater. Eng. 288 (7), 553 (2003). 